\title{
Sócrates y Sade: una perversión (o el escándalo de la filosofía)
}

\section{Gustavo Luna}

\begin{abstract}
Por la muerte, por el miedo a la muerte empieza el conocimiento del Todo. De derribar la angustia de lo terrenal, de quitarle a la muerte su aguijón venenoso y su aliento de pestilencia al Hades, se jacta la filosofía. [...] Deja que el cuerpo quede a merced del abismo, pero la libre alma sale revoloteando.
\end{abstract}

Franz Rosenzweig.

$\mathbf{E}$ 1 sujeto es vulnerable. ${ }^{1}$ Y lo es más aún si se apresta a dejarse decir por el otro, si se pone a su disposición, si está desnudo y francamente abierto a la palabra del otro; hasta tal punto que puede llegar a dudar de sí, a creerse o verse como el otro, a no saber de sí, a perder su identidad en el otro o, peor aún, a encontrarse [a sí mismo] en el otro. Y digo "peor aún" porque encontrarse a sí mismo en el otro es tanto como perder la propia identidad, dejar de ser quien se es, dejar de reconocerse. En esas condiciones se está a merced de la violencia: precisamente ahí, en el riesgo de perderse, el ser propio está siendo removido, vaciado, abandonado; su propiedad puesta en fuga. Al encaminarse a su perdición, el sujeto habría de dejar un rastro en su camino, huellas del camino por donde se ha perdido; en este su andar errante (no simplemente errado, pues no diremos que se ha equivocado sino solamente que no es ya su camino) el sujeto deja ser: se va perdiendo a sí mismo, yéndose por las ramas. Al removerle una y otra vez de su lugar de estancia el sujeto entregado se des-gasta. Gastar ser (gastar-se) quiere decir aquí tanto como derramar ser, sobre abundar en el darse (Gegebung); ${ }^{2}$ diseminarse o, lo que es lo mismo, liquidar al sujeto, hacerle

1 "El Yo (Moi), de pies a cabeza, hasta la médula de los huesos, es vulnerabilidad" (Emmanuel Lévinas, Humanismo del otro hombre. Madrid, Caparrós, 1998, p. 89).

${ }^{2}$ Si ya Husserl se ha ocupado de forjar un término, Gegebenheit, para lo que está ya

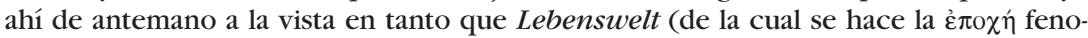
menológica), precisamente como estando ahí, esto es, estáticamente en cuanto objeto (Gegenstand), quisiera hacer referencia con la palabra Gegebung al dar-se de lo que se da en la presencia (Anwesenheit) y no ya al mero ser dado (gegeben sein) de lo ahí puesto (gesetzt). Lo cual no implica ya un sujeto que da o dona sino que se da y no es 
fluir (dilatarle, diferirle, re-trasarle; re-trazar el camino de su gasto, desviarle del camino); esto es, llevarle por otro camino y hacia su destrucción. Así pues, la remoción del sujeto será equivalente a su dilación, su pérdida igual a su liquidación. Seguiría ahí pero no ya firme y seguro sino más bien fluido, iría ciertamente siempre a menos, ya no en cuanto sujeto fundante que todo lo domina desde el cogito sino derramándose en tanto ser debilitado, venido a menos, pervertido. Sujeto alterado, depravado. La entrega del sujeto comporta el abandono de su propia figura.

Naturalmente, para caer en semejante estado hace falta que uno se vea seducido por el otro, ${ }^{3}$ hace falta querer darle el ser al otro; estar poseído por él como quien escucha a las sirenas. ${ }^{4}$ Una canción hechicera y la promesa del descanso en un prado florido lo puede todo sobre la voluntad humana, sobre todo cuando se viven tiempos de penuria. La recomendación de la diosa al héroe es clara: no les escuches y, si lo haces, no te dejes llevar, de otro modo estás perdido.

En el año 399 a. C., un hombre, cuya fama llega hasta el día de hoy y se extenderá seguramente hasta el mañana sin término, fue acusado y condenado a muerte por poseer este poder seductor y por pervertir (o llevar a la perdición) a los jóvenes, no con música sino con su sola palabra. Ese hombre es Sócrates. ¿Cómo pudo una persona, la vida de un pensador, provocar un escándalo tal que incluso nosotros ahora, hoy mismo, aquí mismo, lo celebramos?

La Apología de Sócrates (trátese de la defensa que hace Sócrates de la sociedad ateniense, de la fallida defensa de sí mismo o del encomio de su figura por obra de Platón en el diálogo que lleva su nombre) es, en cualquier caso, la teatralización del escándalo. La puesta en escena de una ofensa. ¿En qué consiste la violencia socrática? ¿Cuál es su delito, cuál su violación? Para empezar habría que decir que el oficio de Sócrates es obsceno, ${ }^{5}$ dice cosas que no le han sido preguntadas y sin que los demás quieran siquiera oírlas. La

dado. (Como se sabe, las terminaciones -heit y -keit, en alemán, hacen referencia la una a algo estático y la otra a algo sustantivado, posturas de las que pretendo alejarme al colocar la terminación -ung, cuyas connotaciones son más bien activas o transitivas.)

3 "Más que nada, estrategia de desplazamiento (se-ducere: llevar aparte, desviar de su vía)..." (Jean Baudrillard, De la seducción. Madrid, Cátedra, 1998, p. 27).

${ }^{4} C f$. Homero, Odisea. Madrid, Gredos, 2000, XII, 39-46, p. 190.

5 “'Obscaeini interpres funestique omnis auctor'. Obscaenum ductur ab scaena. [...] Quare turpe ideo obscaenum, quod nisi in scaena palam dici non debet". "Intérprete y garante de un presagio torpe [obscaenum] y funesto. Obscaenum deriva de scaena (escena). [...] Por eso, lo torpe es denominado obscaenum, porque no debe decirse así públicamente más que en el escenario." "...un presagio torpe [obscaenum] es un presagio funesto [turpe]..." (Cf. Marco Terencio Varrón, De lingua latina. Barcelona, Anthropos, 1990, vII, 96-97, pp. 277-279). 
pretensión socrática de decir la Verdad, no solamente con mayúsculas (en sustantivo), también con-todas-sus-letras, ofende. Esto es lo obsceno, no que-

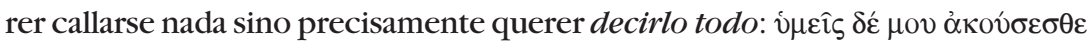

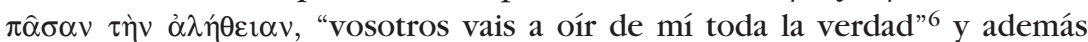
despojada de todo adorno, esto es, desnuda: sin censura y, en consecuencia, de manera injusta ${ }^{7}$ abrupta, perentoria, torpemente. ${ }^{8}$ La puesta en escena de la verdad es justo (in-justo) lo que es visto como ob-scae-nos, obsceno: ${ }^{9}$ lo

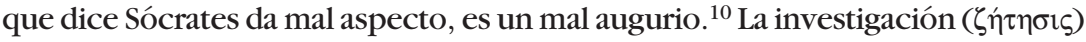
a la que el Oráculo de Delfos le invita comporta un asunto desagradable. Este viaje de Sócrates (ese salir de sí para regresar a sí fortalecido) es el acto de vio-

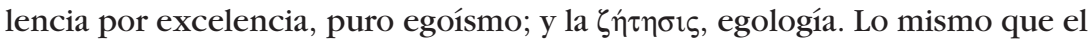
viaje de Odiseo, ese ser perdido que a vueltas consigo mismo regresa a la patria para enfrentarse a los pretendientes de su amada, asimismo se enfrenta este $\rho \eta ́ \tau \omega \rho$, después de su largo viaje a través de la exposición del otro (de su puesta en evidencia de "lo que es" ese otro según él) se enfrenta a estos falsos

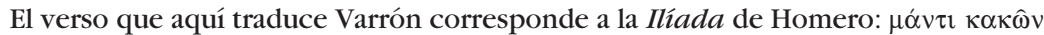

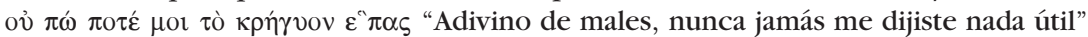
(Homero, Ilíada. Madrid, Consejo Superior de Investigación Científica, 1991, I, 106, p. 9). Calcas dijo a Agamenón (en realidad a Aquiles, es él quien pregunta aunque resulta agraviado el otro) una verdad que aquél ni quería oír ni pidió: "suya es la culpa de que la peste azote al ejército aqueo”, pues por capricho tiene a Criseida como presa del botín y no desea dejarle ir con su padre.

${ }^{6}$ Platón, Apología de Sócrates. Trad. y notas de J. Calonge R. Madrid, Gredos, $1981,17 b 7-8$.

${ }^{7}$ Por supuesto, me remito al sentido etimológico: "Ex cuo licet videre iurgare esse ab iure dictum, cum cuis iure litigaret; ab quo obiurgatis quid it facit iuste": "De ello se desprende que iurgare (entablar un proceso) deriva de ius (derecho): es cuando alguien litiga (litigare) ajustándose al derecho (iure); de aquí que uno censura (obiurgare) cuando lo hace con justicia (iure)" (M. T. Varrón, op. cit., VII, 93, pp. 276-277).

8 "no oiréis bellas frases, como las de éstos, adornadas cuidadosamente con expresiones y vocablos, sino que vais a oír frases dichas al azar con las palabras que me vengan a la boca..." (Platón, Apología de Sócrates, 17b9-c1).

9 Sub voce: "obscenus: (obscaenus) -a, -um: terme de la lange augurale "de mauvais augure"; par suite, dans la lange courante, "d'aspect laid ou affreux; qu'on doit de éviter ou cacher; obscéne"; [...] la variation obscaenus rappelle celle de scena, scaena" (A. Ernaut y A. Meillet, Dictionnaire Etymologique de la Langue Latine. Histoire des Mots. París, Klincksieck, 1967).

${ }^{10}$ De aquí resulta perfectamente comprensible la denuncia de Nietzsche: "Antes de Sócrates la gente, en la buena sociedad, repudiaba los modales dialécticos: eran considerados como malos modales, le comprometían a uno. A la juventud se le prevenía contra ellos. También se desconfiaba de toda exhibición semejante de las propias razones. Las cosas honestas, lo mismo que los hombres honestos, no llevan sus razones en la mano de ese modo" (Friedrich Nietzsche, Crepúsculo de los ídolos. Madrid, Alianza, 1992, p. 40). 
pretendientes de la verdad: mientras que ellos pretenden amarla, él la ama. Igual que un libertino, rechaza las apariencias, la falsa moral, la mojigatería y exige, por el contrario, presencias desnudas. ${ }^{11}$

Sócrates quiere ver al otro libre de ataduras morales, tal cual es, fuera de las normas sociales; le quiere ver abandonado, vulnerable, en el sentido en el que usa esta palabra Emmanuel Lévinas:

La apertura es la desnudez de la piel expuesta a la herida y al ultraje. La apertura es la vulnerabilidad de una piel ofrecida, ultrajada y herida, más allá de todo lo que se puede mostrar, más allá de todo lo que de la esencia del ser puede exponerse a la comprensión y a la celebración. ${ }^{12}$

La vulnerabilidad es, como bien dice Lévinas, "la obsesión por el prójimo o el encuentro con el prójimo". ${ }^{13}$ No es por tanto Sócrates mismo quien se encuentra dispuesto para con el otro, sino el otro, que se ofrece en calidad de víctima para el ultraje. ¿En qué consiste, pues, el crimen socrático? Formulada por el propio inculpado, las dos partes de la imputación dicen así:

Sócrates comete delito y se mete en lo que no debe al investigar las cosas subterráneas y celestes, al hacer más fuerte el argumento más débil y al enseñar estas mismas cosas a otros. [...]

Sócrates delinque corrompiendo a los jóvenes y no creyendo en los dioses en los que la ciudad cree, sino en otras divinidades nuevas. Tal es la acusación. ${ }^{14}$

Según su admirado discípulo, Platón, el oficio de Sócrates es el de partero y no el de pervertidor de menores, les hace alumbrar (concebir una idea), no corromperse. Esto es obvio y no tiene vuelta de hoja. Pero, el embarazo, ¿quién lo provoca? El particular oficio del partero socrático no es simplemente el de recibir al niño; un cierto aspecto del oficio parece confundirse con lo que el

11 “...el monstruo sadiano -que es, no lo olvidemos, un monstruo escrito- propone como realización la literalidad integral: es aquel que dice lo que hace y que hace lo que dice $y$ nunca otra cosa. Es aquel que no tiene hábitos y cuya desnudez remite por entero a un pensamiento trazado" (Philippe Sollers, La escritura y la experiencia de los límites. Valencia, Pre-Textos, 1978, p. 58. Las negritas son mías).

${ }^{12}$ E. Lévinas, op. cit., p. 88.

13 Ibid., p. 89.

${ }^{14}$ Platón, Apología de Sócrates, 19b4-c1 y 24b8-c1, y Platonis Opera, АПОАОГІА

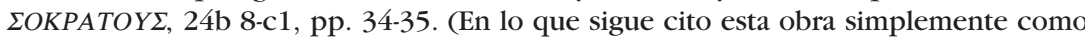
АПОАОГІА.) 
pueblo llano diría que es prostitución, ${ }^{15}$ según reconoce Sócrates mismo en conversación con Teeteto, ${ }^{16}$ y en efecto, el oficio de comadrona que ejerce Sócrates le permite ponerse frente al otro mientras éste se abre (cerrando el paso o abriéndolo, todo depende de la calidad del "producto", que es como se llama en medicina al recién parido), dicho en latín, Sócrates es el obstetrix, es "quien se pone enfrente", técnicamente ejerce la obstetricia. Esto no sería mayor problema si fuese sólo él quien se mostrase desnudo y abierto frente al otro, quizás sería entonces un exhibicionista o incluso un pervertido, pero no un perverso ni un pervertidor; sin embargo, sucede justamente lo contrario, es él quien pide al otro que se muestre ante sí una vez que ha sido puesto en un embarazo por su manera de preguntar, es él quien desnuda (al alma, claro) y seduce con un $\varepsilon$ $\lambda \varepsilon \gamma \chi \circ \varsigma$, en una palabra, exige entrega. ${ }^{17}$

¿Qué hay de malo en el modo socrático de investigar? En la primera parte de la acusación (que es, además, la que más le importa a Sócrates) se dice que "hace fuertes argumentos débiles". De esta imputación se defiende señalando que lo que él hace es mostrar al que cree saber que no sabe. El juego es digno de nota. "Hacer fuerte un argumento" significa "darle fuerza", por tanto, hacerle más capaz de violencia, más agresivo, más ofensivo. La lectura favorable al acusado diría que se trata de hacer fuerte un argumento para resistir cualquier embate, poniendo así el argumento a la defensiva, de esta forma, las pruebas a favor del argumento constituirían un contra-ataque. Ahora bien, ¿quién hace qué en el diálogo socrático? Indudablemente, quien hace las preguntas es quien está al ataque, quien responde contra-ataca. ¿Y cuál es la intención de Sócrates al poner al otro a la defensiva? Afirmar o afianzar su propia posición. La consecuencia natural es la afirmación del propio yo, de la propia existencia, y el debilitamiento de la existencia del otro: su ser (que, para

${ }^{15}$ Prostituir: de "pro-stare", del mismo sentido que prostituire, pero derivado de stare más directamente; pro-stare: "estar ahí delante". (Las cursivas son mías).

${ }^{16}$ Platón, Teeteto o de la ciencia. Barcelona, Anthropos, 1990, 150a1-9, p. 85: "SÓC. Seguramente no. Sólo por lo injusta e indigna que es la cohabitación zopenca de hombre y mujer, las comadres, mujeres dignas al fin y al cabo, se abstienen de la alcahuetería, y luego también de la casamentería, no fuera que ésta les hiciere caer en la sospecha de aquélla. Propiamente sólo a las comadres que lo son de verdad corresponde el arte de juntar matrimonios. TEET.: Parece. SÓC.: De modo que hasta aquí el arte de las comadres, que es en verdad inferior a mi actividad." [C $f$. Platón, Teeteto. Madrid, Gredos, 1988, 149d-e, pp. 188-189; donde en vez de "alcahuetería" dice "prostitución".]

17 "Me he extendido, mi buen Teeteto, contándote todas estas cosas, porque supongo -como también lo crees tú- que sufres el dolor de quien lleva algo en su seno. Entrégate, pues, a mí, que soy hijo de una partera y conozco este arte por mí mismo, y esfuérzate todo lo que puedas por contestar a lo que yo te pregunte" (ibid., 151b 6-c 2, p. 193). 
Sócrates, es mero aparecer) es puesto en duda; quien le escucha y no tiene argumentos fuertes para defender sus creencias, corre el riesgo de perder su identidad, su ser, su fuerza. Expresado brevemente, el juego socrático consistiría en esto: mi argumento débil ("yo no sé ni poco ni mucho") es más fuerte que el más fuerte de los argumentos (aquel que dice "yo sé"), pues el mío siempre sale indemne, mientras que el otro siempre puede resultar vulnerado, debilitado. ${ }^{18}$ He ahí el crimen socrático, su depravación y su enfermedad ( $m o r$ bo, en latín): es un resentido. Calumnia los valores ajenos; ${ }^{19}$ de hecho, los valores de la clase dominante (políticos, poetas, artesanos), ${ }^{20}$ es el tipo débil que valora vulgarmente. ${ }^{21}$ En efecto, así es como define Max Scheler al resentido:

La estructura: "relación entre el valor propio y el ajeno", se convierte, para el "vulgar", en la condición selectiva de su percepción de los valores. No puede aprehender en otros ningún valor sin tomarlo a la vez como "superior" o "inferior", como "mayor" o "menor" que su propio valor; sin medir a los demás consigo y a sí mismo con los demás. ${ }^{22}$

Sócrates dice que, según lo que él interpreta del Oráculo, el dios le ha ordenado "vivir filosofando y examinándome a mí mismo y a los demás";23 se trata precisamente de poner al sujeto por encima de las instituciones y de las personas; no de ocuparse de la democracia en su ejercicio diario, sino de dictar (decir) la forma que le conviene "según yo creo" 24 con las mejores

18 Aquí ubico la afirmación nietzscheana de que Sócrates cobra venganza: "El dialéctico deja a su adversario la tarea de probar que no es un idiota: hace rabiar a los demás, y al mismo tiempo los deja desamparados. El dialéctico vuelve impotente el intelecto de su adversario" (F. Nietzsche, op. cit., p. 41).

${ }^{19}$ Cf. Francisco Rodríguez Adrados, La democracia ateniense. Adaptado por Manuel Gonzalo. Madrid, Alianza, 1985, p. 391. (Alianza Universidad, 107)

${ }^{20}$ Según Scheler: "El resentimiento queda circunscrito por su base a los siervos $y$ dominados, a los que se arrastran y suplican, vanamente, contra el aguijón de una autoridad" (Max Scheler, El resentimiento en la moral. Madrid, Caparrós, 1998, p. 24). Se podría objetar que Sócrates ni se arrastra ni suplica, que es justo lo que parece que quisieran sus acusadores ver que hiciera (Platón, Apología de Sócrates, 38d5 y ss.) y que él dice claramente que no va a hacer, pero simplemente cambia el método (como sabe hacerlo) y pide una y otra vez que se le deje hablar como acostumbra y que se le responda, como está acostumbrado que ocurra; y cada vez que pide esto produce indignación, rumor y escándalo, como no se le complace, no seduce a nadie.

${ }^{21}$ M. Scheler, op. cit., p. 31.

22 Idem.

${ }^{23}$ Platón, Apología de Sócrates, 28e5-6, p. 42: "

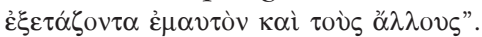

${ }^{24}$ Ibid., 36c-d. 
intenciones ("razonando el crimen", ${ }^{25}$ como diría Sade), inspirado por $\theta \varepsilon \hat{\imath} o ́ v$

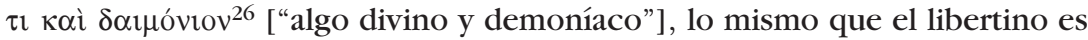
inspirado por la naturaleza. ${ }^{27}$ Así como el libertino se pasea desnudo por las calles causando horrores entre aquellos que andan bien vestidos (de convenciones sociales), se pasea Sócrates desnudo (de cuerpo a veces, de alma siempre) entre los atenienses, impúdica y desvergonzadamente. Ciertamente no es maestro de nadie, no enseña, pero bien que se deja ver y desnuda a los demás; con ello no hace sino cumplir el precepto fundamental del libertino:

En la sociedad sadiana, no existen esas alusiones, provocaciones y fintas, de que es objeto nuestra vestimenta: el amor queda inmediatamente al desnudo; a modo de strip-tease, sólo tenemos el “iDescúbrase!” brutal con el que el libertino ordena a su súbdito que se coloque en posición de ser examinado. ${ }^{28}$

Naturalmente, lo que Sócrates enseña, fomenta o, para decirlo en lenguaje mántico, inspira es el horror y el escándalo. Arrogándose el derecho de decirlo todo, de "no abandonar nada a las apariencias", ${ }^{29}$ probablemente suscribiría con gusto la siguiente sentencia del Divino Marqués:

Indudablemente vamos a humillar aquí el orgullo del hombre, rebajándolo al rango de todas las demás producciones de la naturaleza, pero el

25 "Para Sade sólo hay erótica si se "razona el crimen"; razonar, quiere decir filosofar, disertar, arengar, someter el crimen (término genérico que designa todas las pasiones sadianas) al sistema del lenguaje articulado..." (Roland Barthes, Sade, Fourier, Loyola. Madrid, Cátedra, 1997, pp. 37-38).

26 “...hay junto a mí algo divino y demónico; esto también lo incluye en la acusación Méleto burlándose. Está conmigo desde niño, toma forma de voz y, cuando se manifiesta, siempre me disuade de lo que voy a hacer, jamás me incita" (Platón, Apología de Sócrates, 31d2-4, p. 170).

${ }^{27}$ Incluso comparten el mismo destino: "Mi manera de pensar es el fruto de mis reflexiones; está en relación con mi existencia, con mi organización. No tengo el poder de cambiarla, y aunque lo tuviera, no lo haría. Esta manera de pensar que censuráis es el único consuelo de mi vida; me alivia todas mis penas en la cárcel, constituye todos mis placeres en el mundo, y me importa más que mi vida. La causa de mi desgracia no es mi manera de pensar, sino la manera de pensar de los otros" (El marqués de Sade, Oxtiern o las desdichas del libertinaje. El filósofo en su opinión. Trad. de Jacqueline y R. Conte. Madrid, Cuadernos para el diálogo (Colección Libros de Teatro, 25), 1970; (de una carta a su esposa) p. 11. Compárese con la Apología, passim.

${ }^{28}$ R. Barthes, op. cit., p. 30.

${ }^{29}$ J. Baudrillard, De la seducción, p. 38. 
filósofo no halaga las pequeñas vanidades humanas; ardiente perseguidor de la verdad, la discierne bajo los tontos prejuicios del amor propio, la alcanza, la desarrolla y la muestra audazmente a la tierra asombrada. ${ }^{30}$

El oficio de Sócrates es el de humillar al débil, no con el propósito de humillarle, ${ }^{31}$ diría el filósofo, pero sí con el fin de que el humillado se dé cuenta de su debilidad y pase entonces al ataque: ${ }^{32}$ después de ser sometido, debe someter, de víctima a victimario, de masoquista a sádico (sadiano). Porque ciertamente, dice Sócrates, se encuentra placer en el crimen, ${ }^{33}$ en esta transvaloración que pone arriba lo que los demás ponen abajo y que pone abajo lo que aquellos ponen arriba. ${ }^{34}$ Unas veces soy yo, otras, el otro. ${ }^{35}$ Los jóvenes que le escuchan, y por quienes siente una "amorosa predisposición", como la llama Alcibíades en el Banquete, ${ }^{36}$ son heridos por los preciosos discursos filosóficos de este Sátiro en donde más duele, pues "son cosa más cruel que una víbora, cuando se apoderan de un alma joven no sin cualidades naturales, y la fuerzan a hacer o decir cualquier cosa..." ${ }^{37}$ Hay, pues, en la conversación, en el diálogo socrático, un hostigamiento, la saturación obscena no del cuerpo, como ocurre para Sade, sino del alma, que debe ser capaz

${ }^{30}$ Marqués de Sade (Donatien Alfonse François), La filosofía en el tocador. Madrid, Valdemar, 2000, p. 104.

${ }^{31}$ Véase si no, la recriminación de Alcibíades en Platón, Banquete, 216d-e y 219c.

${ }^{32}$ Cf. Platón, Apología de Sócrates, 33b: "me ofrezco, para que me pregunten..."

33 "¿Por qué realmente gustan algunos de pasar largo rato a mi lado? Lo habéis oído ya, atenienses; os he dicho toda la verdad. Porque les gusta oírme examinar a los que creen ser sabios y no lo son. En realidad es agradable" (Platón, Apología de Sócrates, 33c, p. 173).

34 "Tenemos que preservar aquí la originalidad de lo que llamamos Perversión y decir que, al nivel en el que la entendemos, denuncia la simple reversibilidad perversión-neurosis. Lo mismo que Nietzsche veía en la perversidad la realización concreta de toda "espiritualidad", también el pensamiento teórico -aquel que es susceptible de modificar las condiciones reales del pensamiento- nos parece que debe ser esencialmente perverso. La perversión es el pensamiento teórico mismo, es decir, que es la razón de toda realización práctica" (P. Sollers, op. cit., p. 53. El subrayado es mío).

35 "Esta regla es capital, en primer lugar porque asimila la erótica sadiana a un lenguaje realmente formal, en el que sólo hay categorías de acción y no grupos de individuos, lo que simplifica mucho la gramática: el sujeto del acto (en el sentido gramatical de la palabra) puede ser un libertino, un ayudante, una víctima, una esposa [...] Ya que todo el mundo puede ser sodomita y sodomizado, agente y paciente, sujeto y objeto, ya que el placer es posible en todas partes [...]" (R. Barthes, Sade, Fourier, Loyola, p. 42).

36 Platón, Banquete. Introd. de Carlos García Gual, trad. y notas de Fernando García Romero. Madrid, Alianza, 2000, 216d, p. 132. (El libro de bolsillo, 8213)

${ }^{37}$ Ibid., 218a, p. 135. 
de excavar en sus profundidades para decirlo todo, para dar nombre al todo, para nombrar la totalidad. ${ }^{38}$ En este sentido, el lenguaje de Sócrates es totalitario: absolutiza los valores humanos. ${ }^{39}$ La subversión que lleva a cabo el filósofo no es una simple inversión, es la radicalización de los valores: va al fondo, a la raíz, y la expone a la luz; lo que no podría causar sino la descomposición de lo expuesto, su desecación; pues, esto es claro, su lugar natural no es ese sino el fondo oscuro de donde es violentamente arrancado. De ahí que no sea bien visto que Sócrates hable de lo que (mal que bien) le ha sido confiado: el ser del otro. Se explica además así porque es visto como un "mal sujeto": el $\delta \rho \hat{\alpha} \mu \alpha$ socrático (el papel que le toca jugar en la representación teatral del crimen) es el de sátiro, ${ }^{40}$ es el sujeto que corroe, ofende y hiere con male-

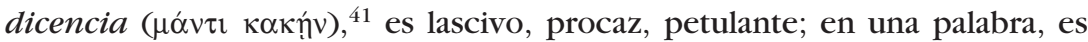
monstruoso. Y es que en efecto se sabe que Sócrates era feo, más aún, Alcibíades dice que no sólo se parece a un Sátiro, ${ }^{42}$ sino que muy particularmente se parece a Marsias, ${ }^{43}$ de quien hallamos una descripción de su figura en Calístrato. ${ }^{44}$

${ }^{38} C f$. F. Rodríguez Adrados, op. cit., pp. 385-407; especialmente las pp. 403 y 404. La filosofía de Sócrates es calificada ahí de "moralismo totalitario".

${ }^{39}$ La prueba de ello puede leerse en Gregory Vlastos, "Socrates", en William J. Prior, ed., Socrates. Critical Assessments. Londres/Nueva York, Routledge, 1996, vol. I, p. 141. 4 vols. [Vol. I The Socratic Problem and Socratic Ignorance.]

${ }^{40} \mathrm{El}$ sátiro es un demón de la naturaleza. Representa las fuerzas de la naturaleza. Se les rendía culto en Arcadia, en los centros de adoración del Dios Pan ("el de los pies de cabra"). Sus ritos provocan la posesión y la metamorfosis en el animal sagrado (cabra), así como crisis de entusiasmo. De dichas danzas nacieron el ditirambo, el drama satírico y la tragedia (lo que no cuadra nada mal con la argumentación en la que se encuentran envueltos Agatón, Aristófanes y Sócrates al final del Banquete -223b-c- y en la cual les hace reconocer que "quien con arte es autor trágico, también lo es cómico").

41 "The individual remains the same throughout: the same ugly, impudent, amusing, exasperating, unstoppably loquacious, relentlessly intellectual man, who dominates every company he enters by the force of his personality and the energy of his mind" (G. Vlastos, op. cit., p. 138. Las cursivas son mías).

42 "La raza libertina sólo existe a partir de los treinta y cinco años de edad; aunque repugnantes desde todos los puntos de vista si son viejos (caso más frecuente), los libertinos pueden tener una buena planta, fuego en la mirada, aliento fresco, pero esta belleza se compensa por un aspecto cruel y malvado. En cuanto a los sujetos de la depravación, son bellos si son jóvenes, horribles si son viejos, pero en los dos casos son útiles para la lujuria" (R. Barthes, Sade, Fourier, Loyola, p. 31).

${ }^{43}$ Cf. Ovidio, Metamorfosis. Madrid, Cátedra, 1999, Iv, 382 y ss., pp. 404-405. Asimismo: Heródoto, Historia. Ed. y trad. de Manuel Balasch. Madrid, Cátedra, 1999, VII, 26, p. 664. (Letras universales, 274)

${ }^{44}$ Filóstrato el viejo, Imágenes. Filóstrato el joven, Imágenes. Calístrato, Descripciones. Ed. de Luis Alberto de Cuenca y Miguel Ángel Elvira. Madrid, Siruela, 1993, p. $181,1,4$. 
Ninguna delicadeza había en el cuerpo; la solidez de los miembros le había arrebatado la elegancia, endurecido su forma con la estructura de sus músculos; pues, mientras la piel blanda y los miembros delicados convienen a una bella muchacha, el aspecto de un sátiro es tosco, como de genio montaraz que brinca en honor de Dioniso.

Pero no solamente su aspecto físico es poco delicado (por decir lo menos), su lenguaje tampoco es para nada elegante o cuidado (no hay metáforas, han sido abolidas; no hay retórica, si por retórica se entiende la "habilidad para hablar"). ${ }^{45}$ El personaje (persona) Sócrates, el sátiro, está ahí, en escena, para zaherir y mortificar con su mordacidad, y su indumentaria -nótese el oxímoron- es la desnudez; torcedura metafísica. El sesgo metafísico del filósofo, su desviación del papel, consiste justo en no llevar el disfraz del sátiro (la piel de cabra): hacer las cosas al revés es para él hacerlas al derecho. ${ }^{46} \mathrm{Es}$, como el libertino, sin-vergüenza. ${ }^{47}$ ¿Hacia qué apunta la des-vergüenza socrática? En otras palabras, ¿cuál es la intención de Sócrates al mostrarse desnudo y querer desnudar a cualquiera con el que se encuentre? Lo que quiere es inspirar un deseo, ${ }^{48}$ que le dirijan una "mirada erótica"; quiere pues ser amado, pues él mismo reconoce que le falta $\sigma \omega \varphi \rho о \sigma u ́ v \eta,{ }^{49}$ no es sabio sino solamente en cuanto a esa "(in)cierta sabiduría" 50 humana: la de reconocer que no sabe ni cree saber lo que no sabe. De manera que éste es el resultado

${ }^{45}$ Cf. Platón, Apología de Sócrates, 17a-18a. Con lujo de detalle puede leerse en el Banquete de Platón (ed. cit., 221d 8-e 10) la descripción de Alcibíades. Como se verá, el texto sadiano termina justo donde mismo: el libertino busca la manera de ofender a la naturaleza pero, si la esencia de la naturaleza es el crimen y la violencia, la mayor ofensa (por tanto, la mejor tarea del libertino) será la de actuar contra la naturaleza; esto es, virtuosamente. Además, el mismo reproche que se le hace aquí a Sócrates, ser monótono, es el que se dirige a los textos del Marqués de Sade quien, si se lee atentamente, dice justo lo contrario de lo que sus textos expresan.

46 "La verdad que se obtiene como rebote, en la eclosión de verdades y por el deterioro de ese real 'al derecho', viene a ser el revés de lo Verdadero. Pues todo sucede como si, en metafísica, el revés significara el derecho" (E. Lévinas, op. cit., p. 65).

47 "...habría que suponer entonces, en cuanto al libertino, una des-represión originaria que libera de una vez la posibilidad de decir en un decirlo todo sin reserva que tiene la violencia de lo obsceno y que es su ley paradójica: apuesta de desplegar lo interdicto en la red del discurso" (M. Hénaff, Sade: la invención del cuerpo libertino. Barcelona, Destino, 1980, p. 52).

48 "El discurso amoroso es antes que nada una mántica: una adivinación; descifrar correctamente los signos que emite el cuerpo amado para conocer lo que hay de la intención que lo habita" (ibid., p. 24).

${ }^{49}$ Gregorio Luri Medrano, El proceso de Sócrates. Madrid, Trotta, 1998, pp. 102 y ss.

${ }^{50}$ Ibid., cap. 4, pp. 83-90. 


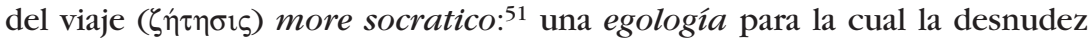
pasa por virtud y en la cual el sujeto es disuelto, diseminado en la lujuria de la razón, en la "enciclopedia del exceso": "El texto sadiano realiza esa mixtura, ese monstruo: el filósofo aventurero, la academia burdel, el saber desenfreno, la disertación orgía; es sólo atreviéndose a decir demasiado como se hace verdaderamente posible decirlo todo..." 52

Y es éste el atrevimiento de Sócrates, que pretende decir toda la verdad a los atenienses y que se precia de decir que "la verdad es así, como yo digo". .53 Con esta frase se lleva a la boca él mismo la cicuta; por su falta de sabiduría y por su exceso en el cuidado de sí mismo, Sócrates fracasa frente a si ${ }^{54}$ pues, de hecho, el infortunio de la virtud no puede tener como consecuencia otra cosa que la entrega de la propia vida; esto es, la muerte. El veneno que bebe es la virtud ${ }^{55}$ que, poco a poco, le envenena el alma (de ahí el resentimiento) hasta matarlo. Sócrates es cruel por necesidad ${ }^{56}$ libertino (incrédulo, ateo, desenfrenado) por convicción y filósofo de oficio. La celebración de su crimen nos ha reunido hoy.

${ }^{51}$ Véase G. Vlastos, op. cit., p. 145.

${ }^{52}$ M. Hénaff, $o p$. cit., p. 72.

${ }^{53}$ Platón, Apología de Sócrates, 38a7-8, p. 180. La versión griega es más escueta, hay que reconocerlo.

54 "Extranjero para sí mismo, obsesionado por los otros, inquieto, el Yo (Moi) es rehén, rehén de la propia recurrencia de un yo que no cesa de fallarse a sí mismo. Y, sin embargo, de esta manera, más próximo a los otros, más obligado, agravando su propio fracaso ante sí mismo" (E. Lévinas, op. cit., p. 93).

55 "En lo cual hay una reducción al absurdo de la "filosofía" de Sade, pues admitiendo que el objetivo de la naturaleza sea la destrucción, y que ninguna acción destructiva puede irritarla u ofenderla (Sade mismo reconoce: "La imposibilidad de ultrajar a la naturaleza es, según mi punto de vista, el suplicio más grande del hombre"), el supremo insulto que se le podría dirigir, y del cual el sádico podría legítimamente derivar un placer de trasgresión, sería justamente... ¡La práctica de la virtud!" (Mario Praz, La carne, la muerte y el diablo en la literatura romántica. Trad. de Rubén Mettini. Barcelona, Quaderns Crema, 1999, p. 200. (El acantilado, 8)

56 " [...] el hombre-de-letras, lo bastante filósofo como para decir la VERDAD, supera esos disgustos y, cruel por necesidad, arranca despiadadamente los aderezos supersticiosos con los que la imbecilidad embellece la virtud y muestra descaradamente al hombre ignorante que se engaña, el vicio en medio de los encantos y el poder que lo rodean y que sin cesar lo persiguen" (Marqués de Sade, Justine, vol. I, pp. 3-4 apud M. Praz, op. cit., p. 196). 